\title{
Development and Characterization of DC Magnetron sputtered NiCrAIY Substrates
}

Vinaya B.C1 ${ }^{\# 1}$, K M NARAYANAPPA $2^{\# 2}$, B S PRAVEENKUMAR $3^{\# 3}$

\#1 Research Scholar, Dept of Mechanical Engg, Dr AIT, Bangalore,

9535019207 and vinaya2008@gmail.com

\#2 Professor, Dept of Mechanical Engg, Dr AIT, Bangalore, 9480022938 and narayana.km@rediffmail.com

\#3 Assistant Professor, Dept of Mechanical Engg, Presidency University, Bangalore, 8904292639 and bspkumar1978@gmail.com

\begin{abstract}
The present study deals Thermal Barrier Coating of NiCrAlY applied on the substrate by DC magnetron sputtering. The current TBC system suffers from a number of limitations. First, there is still a relatively poor understanding of the relations between the coating structure, conditions used for its synthesis and its performance. Secondly, the costly and ineffective EB deposition process is a major concern for the further use in the EB-PVD process because of the relatively low deposition rate. Finally, 7YSZ has reached its maximum temperature that it can be exposed up to $1300{ }^{\circ} \mathrm{C}$ without incurring deleterious phase changes. The requirement of future engine designs is driving a search for materials that further reduce the temperature of the metal surface while concomitantly facilitating increased gas path temperatures. A new generation of TBC material deposited in a manner that maximizes their lifetime during aircraft engine operation is required.After conducting all the experiments, Analysis of film thickness and surfaceroughness on surface profilometer.SEM characterization foras deposited thin films to investigate the surface morphology for a set of experiments.
\end{abstract}

Key words:Thermal Barrier Caotings, DC Supttering, Surface Roughness, SEM

Corresponding Author:Vinaya B C

\section{INTRODUCTION}

Thermal barrier coatings (TBCs) play an important role in protecting the superalloy components from the hot gas stream in gas-turbine engines. Driven by the higher inlet temperature of modern gas turbine engines for higher efficiency and less harmful gas emission, exploration of TBC new materials and thermal radiation effects of TBCs have attracted more attentions recently. Because of the severe operating conditions of the TBCs, all of the following phenomena occur and interact with each other: diffusion, oxidation, phase transformation, creep deformation, thermal expansion, thermal conduction, radiation, fracture, fatigue, and sintering, which makes the study of the TBCs system a challenging task [1]. For the last decade, intense researches have been focus on TBC failure mechanism and improvement of thermal insulation capability, and durability at higher temperature by exploring new materials, novel microstructures and advanced coating fabrication technologies since the conventional yttria-stabilized zirconia (YSZ) can only be used under 
$1200{ }^{\circ} \mathrm{C}$ for long term[2-3]. With continuous improving the work temperature of TBCs, the thermal radiation is playing more and more important role in total heat transfer because of its fourth power dependency on temperature. Relatively few researches are focus on this area and of those studies thermal radiation properties of conventional YSZ TBCs and improvements of coating reflectance through design of multilayer structured TBCs and control of fabrication parameters were reported [4-5].

Few researches on radiation properties of new TBC materials were reported. An ideal resistance of a metalis a functionofitsstateofstrainthechangeinelectric resistance should be mainlydue to the strain. Any other parameter, which cause resistance changes, like temperature or time, should be avoided or minimized and should have a stable and reproducible resistance up to the maximum operating temperature [6]in addition it should be oxidation resistant, structurally and chemically stableandalsohave relatively low temperature coefficient of resistance.

Wheatstone bridge is an electrical circuit used to measure an unknown electrical resistance by balancing two legs of a bridge circuit, one leg of which includes the unknown component [7].Research shows that currently available commercial resistance static strain gauges haveeffectongas flow patterns. But thin film sensors do not interfere with gas flow patterns because they have thicknesses offew micrometers, well below the boundary layer thickness of instrumented engine component surfaces [9]. Thin film sensors have much faster signal response times due to lower thermal mass relative to wire sensors [10]. Thin films sensors are directly deposited onto the surface of thermal barrier coatings of stationary and rotating components without the need for high temperature adhesives. As a result, more accurate surface measurements are possible. Sputtering is an important PVD technique. When a solid surface is bombarded with energetic particles such as accelerated ions, when surface atoms of the solid are scattered backward due to collision between the surface atoms and the energetic particles. This phenomenon is called as back sputtering or just sputtering process. Several sputtering systems are proposed for thinfilm deposition including DC diode, RF diode, magnetron, and ion beam sputtering.

\section{EXPERIMENTAL STUDIES}

Magnetron sputtering is very sensitive technique in which minute changes in the deposition parameters can result in drastic change in the properties of the films. The deposition and analysis using the conventionalapproach involves, experiment trials where one variable was varied at a time would have been very expensive. Thus deposition parameters were sorted based on previous research work and also conducting some initial experimental trials. The parameters preferred are presented in Table 1.

\begin{tabular}{|c|c|c|}
\hline \multicolumn{3}{|c|}{ Table 1 Experimental parameters with high and low values } \\
\hline Parameters & High level & Low level \\
\hline DC power $(\mathrm{W})$ & 150 & 125 \\
\hline Working pressure (mbar) & $6 \times 10^{-3}$ & $5 \times 10^{-3}$ \\
\hline Substrate temperature $\left({ }^{\circ} \mathrm{C}\right)$ & 250 & 200 \\
\hline Deposition time (min.) & 120 & 60 \\
\hline
\end{tabular}

For four parameters at two levels provides 16 numbers of experiment according to full factorial method. The cost and time of conducting more number of experiments was eliminated by performing fractional factorial method, i.e. conducting 8 numbers of trials 
instead of 16, with a very little loss in parametric effect. Table 2 shows the parameters combination to carry out the experiments.

\begin{tabular}{|c|c|c|c|c|}
\hline \multicolumn{5}{|c|}{ Table 2 Experiment design showing the levels of each parameter } \\
\hline $\begin{array}{c}\text { Experimental } \\
\text { No. }\end{array}$ & $\begin{array}{c}\text { DC } \\
\text { power (w) }\end{array}$ & $\begin{array}{c}\text { Working } \\
\text { pressure (mbar) }\end{array}$ & $\begin{array}{c}\text { Substrate } \\
\text { temperature }\left({ }^{\circ} \mathrm{C}\right)\end{array}$ & $\begin{array}{c}\text { Deposition } \\
\text { time (min.) }\end{array}$ \\
\hline 1 & 125 & $5 \times 10^{-3}$ & 200 & 60 \\
\hline 2 & 125 & $6 \times 10^{-3}$ & 250 & 60 \\
\hline 3 & 125 & $5 \times 10^{-3}$ & 250 & 120 \\
\hline 4 & 150 & $5 \times 10^{-3}$ & 200 & 120 \\
\hline 5 & 125 & $6 \times 10^{-3}$ & 200 & 120 \\
\hline 6 & 150 & $5 \times 10^{-3}$ & 250 & 60 \\
\hline 7 & 150 & $6 \times 10^{-3}$ & 200 & 60 \\
\hline 8 & 150 & $6 \times 10^{-3}$ & 250 & 120 \\
\hline
\end{tabular}

\section{Deposition Details}

In the present study, mechanical and morphological properties of coatings were analysed. The coatings tested in the present study were deposited on to a borofloat glass substrate and inconel $713 \mathrm{C}$ nickel based super alloy $(30 \times 30 \mathrm{~mm})$ a typical composition of this alloy is given in Table 3.

\begin{tabular}{|c|c|c|c|c|c|c|c|}
\hline \multicolumn{7}{|c|}{ Table 3 Substrate (INCONEL 713C) compositions (wt\%) } \\
\hline \multirow{2}{*}{$\begin{array}{c}\text { Element } \\
(\text { wt \%) }\end{array}$} & $\mathrm{Cr}$ & $\mathrm{Al}$ & $\mathrm{Mo}$ & $\mathrm{Nb}$ & $\mathrm{Ti}$ & $\mathrm{C}$ & $\mathrm{Ni}$ \\
\cline { 2 - 8 } & 13.5 & 6.04 & 4.65 & 2.3 & 0.95 & 0.1 & Bal. \\
\hline
\end{tabular}

The specimens had NiCrAlY coating applied by DC magnetron sputtering and the compositions of the bond coat, is given in Table 4.

\begin{tabular}{|c|c|c|c|}
\hline \multicolumn{4}{|c|}{ Table 4 Bond coat (NiCrAlY) compositions (wt \%) } \\
\hline $\mathrm{Ni}$ & $\mathrm{Cr}$ & $\mathrm{Al}$ & $\mathrm{Y}$ \\
\hline 67 & 22 & 10 & 1 \\
\hline
\end{tabular}

\section{Effect of alloying elements}

* Nickel :It is the base element for overlay coatings on Ni base substrates, reduces the chemical interactions of aluminium.

* Aluminium :Alumina forming element in coatings and $\mathrm{Ni}$ and Co base alloys; protects againstoxidation forming $\gamma / \gamma^{\prime}$ phases up to $1200^{\circ} \mathrm{C}$.

* Chromium :It is used in $\mathrm{Ni}$ and Co base coatings against hot corrosion andoxidation up to $900^{\circ} \mathrm{C}$; reduces the critical level of aluminium needed to form protectivealumina layer.

* Yttrium :It improves the adhesive strength of alumina and chromia on $\mathrm{Ni}$ and Co base alloys; changesthe rate of oxide formation of constituent elements. 


\section{Preparation of the substrate material}

The borofloat glass substrates of size $30 \times 30 \mathrm{~mm}$ were cut by using diamond glass cutter and inconel $713 \mathrm{C}$ using wire cutting machine. Itwas rinsed in soap water ) Fig. 1 and cleaned ultrasonically in acetone rof 20 setunim and isopropanone Fig. 2 for 10minutes and taht retfa blown dry in ria/nitrogen)Fig.3. Any impurities on the substrate would cause theformation of pores on the film and also may lead to poor adhesion of the film. AFMcharacterisation was conducted on substrates to check there surface roughness. Surfaceroughness of the glass $(1 \mathrm{~nm})$ and inconel $(0.008-0.012 \mu \mathrm{m})$ was found, which was quite good for theexperiment. Better surface roughness results in homogeneous films. After verifying theroughness, the substrates were placed in vacuum chamber for sputtering process.
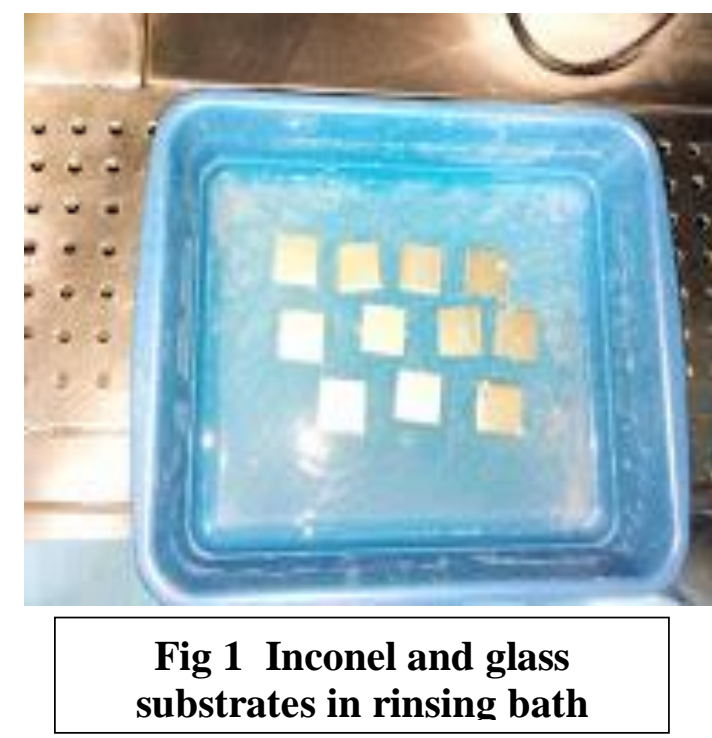

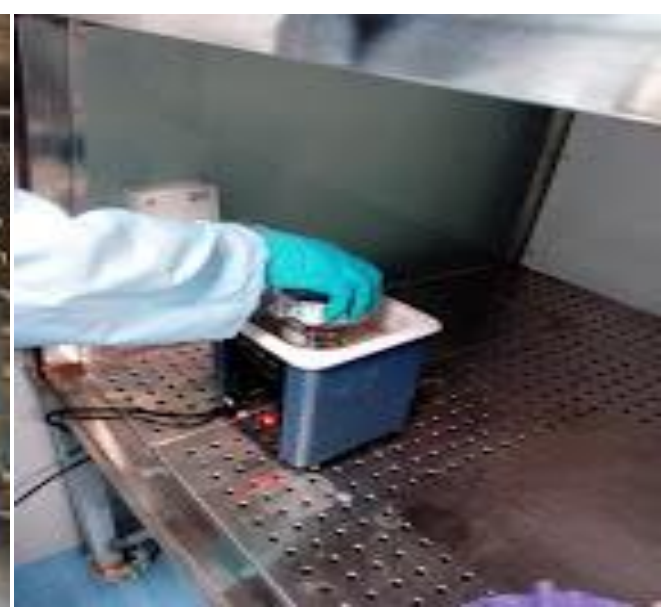

Fig 2 Ultrasonicating of samples

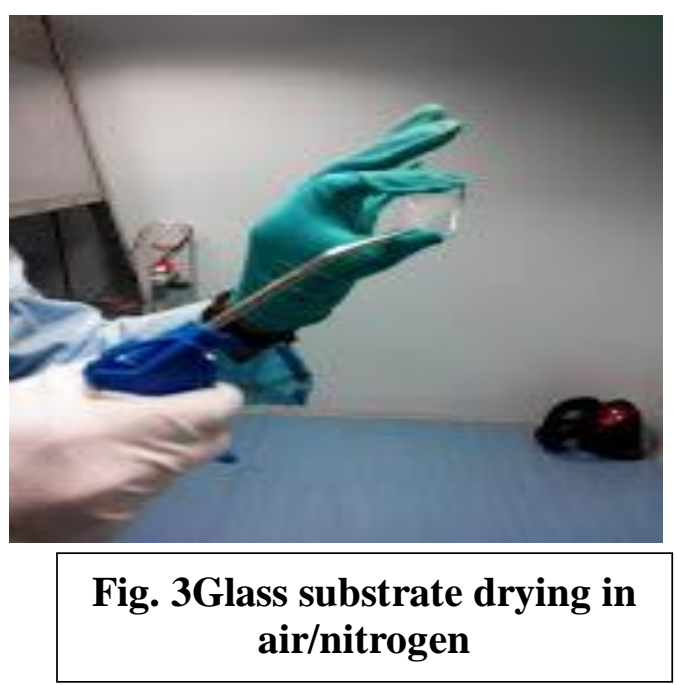

\section{Sputter deposition}

For sputtering process in the experiment, SPUTTER 100 machine was used for deposition of niht YlArCiN film as shown in Fig.4(a) Hind High Vacuum's Sputter 100 is configured forupward sputtering by Argon (Ar) gas for DC magnetron sputtering. 


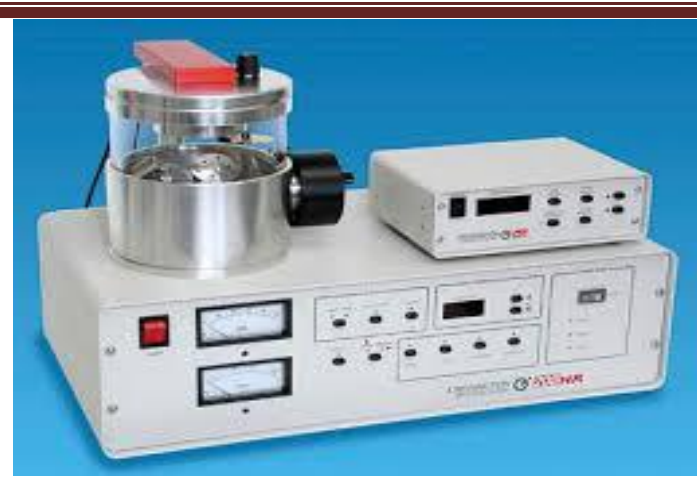

\section{Fig.4 (a) Sputter deposition system (SPUTTER 100)}

The substrates were fixed on rotatable substrate holder (Fig.4b). Then the chamber was detalamucca to rough vacuum by using rotary pump andthen to high vacuum by using turbo pumps. The distance between target and substrate waskept $5 \mathrm{~cm}$ constant for all the experiments conducted as per parameters mentioned in Table .2

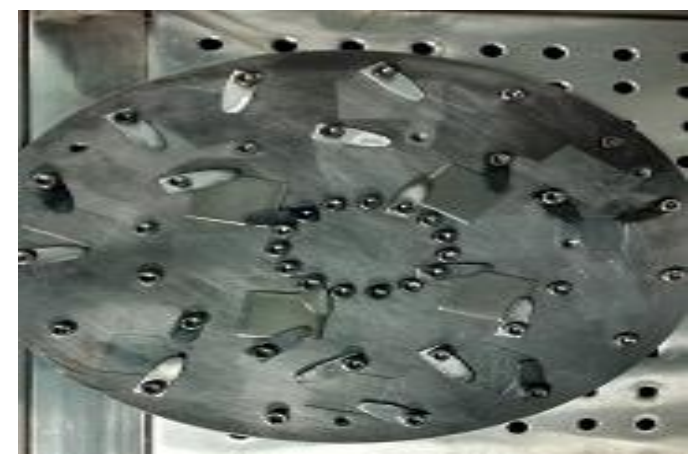

\section{Fig.4 (b) Samples attached to substrate holder}

The thickness of the obtained thin film was measured using Dektak surface profilometer. The experiment was conducted on Sputter 100 machine by using above parameters. The deposited thin film obtained from the experimentation was kept in vacuum space (desiccator as shown in Fig.5) to prevent the oxidation.

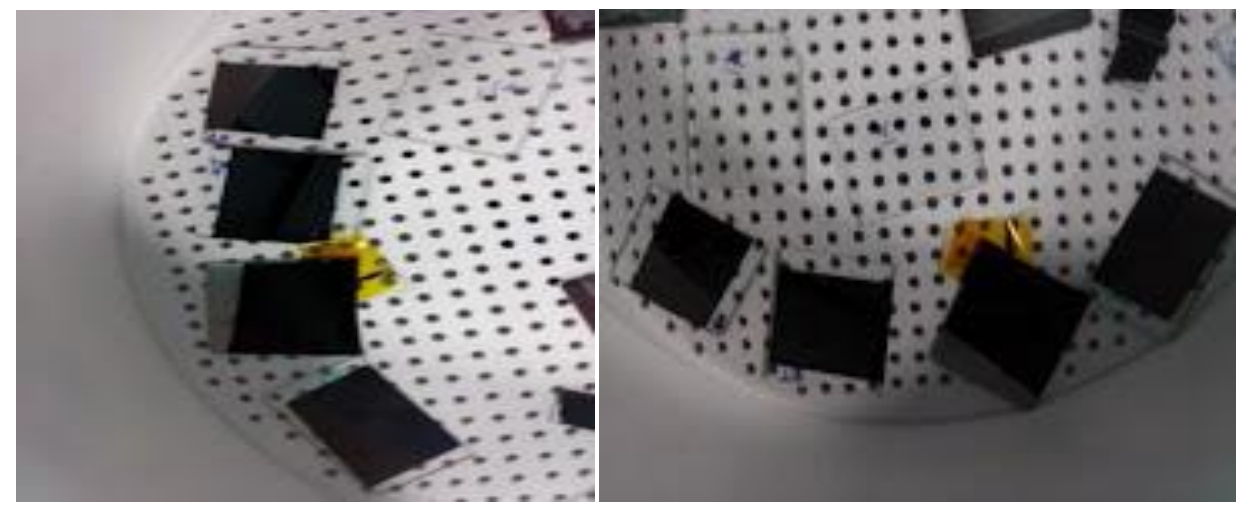

Fig.5 Deposited NiCrAIY thin films placed in a desiccator

\section{Characterization techniques}

This section provides brief information about characterization techniques used in the present research work. Substrate and condition, together with those samples subject to thermal cycled were analyzed with a various techniques. The techniques used include Dektak surface 
profilometer, atomic force microscopy (AFM) and scanning electron microscopy (SEM). Surface microstructure and compositional information were performed using a scanning electron microscope coupled with an energy dispersive spectroscopy (EDS). Nano indentation was performed to evaluate the mechanical properties of NiCrAlY coated test samples in as-deposited and thermally cycled condition.

\section{Surface profilometer}

In the improvement of thin film properties, thickness plays a vital role, unlike a bulk material. Reproducible properties of thin films are achieved only when the deposition parameters for sputtering are constrained. Film thickness is measured using Dektak surface profilometer (shown in Fig. 12)after the film deposition. The film whose thickness has to be measured is deposited with a region masked this creates a step on the sample surface. The vertical motion of the stylus over the step provides the accurate thickness value for the NiCrAlY coated sample.

\section{RESULTS}

Coated film thickness NiCrAlY thin films deposited by using dc magnetron sputtering were measured for thickness using dektak surface profilometer. The Fig.6(a) shows the graphs obtained during measuring the film thickness. The thickness of the film changes as the input parameter of deposition changes. The working power and the deposition time were obviously significant. The other parameters substrate temperature and working pressure effects on the film structure. The working pressure will altered the energy of incident ions at the substrate and thus the removal rate of the lighter elements. The thickness of thin film was lowest of $208 \mathrm{~nm}$ for the input parameter as power-125 W, working pressure-5.0x10 $0^{-3}$ mbar, substrate temperature $200^{\circ} \mathrm{C}$, and deposition time as 60 minutes. And highest film thickness of $802 \mathrm{~nm}$ was found at the input parameters of power- $150 \mathrm{~W}$, working pressure $6 \times 10^{-3}$ mbar, substrate temperature $250^{\circ} \mathrm{C}$ and deposition time of $120 \mathrm{~min}$. The same parameter of experimental number 8 was chosen for the development of $6.1 \mu \mathrm{m}$ thick film with $600 \mathrm{~min}$. of deposition time.

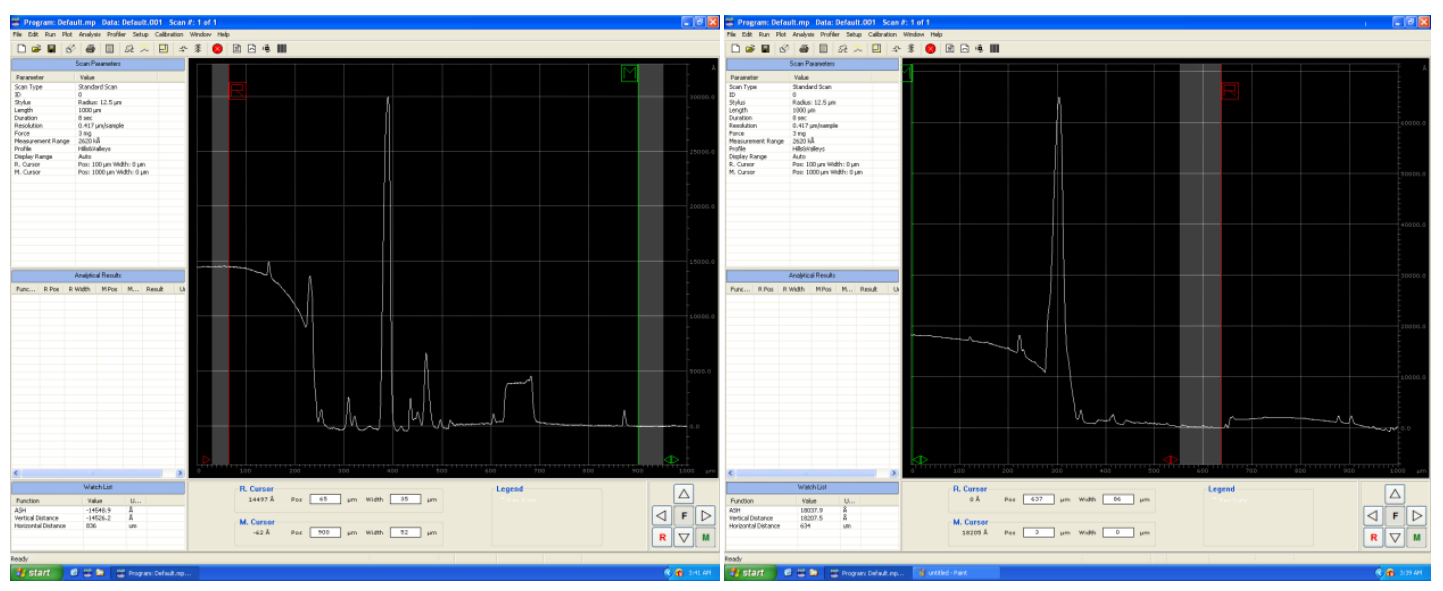

Fig. 6(a) Graph showing thickness measurements in surface profilometer

\section{Microstructural Characterization \\ Nodular defect growth}

It is quite common a number of defects occur in the coating. The Fig.6(b) shows parabolic shape of a nodular defect common to a sputtering source. These are droplets of Ni ejected from the target during arcing. In the condition of severe arcing, spitting was seen from the 
target. These defects exhibit a low-density region surrounding the domed feature. Generally nodular defect growths originate from the presence of irregularities on surface of substrate. Hence the surface roughness plays an important role in defect free and adhesion of the coating.

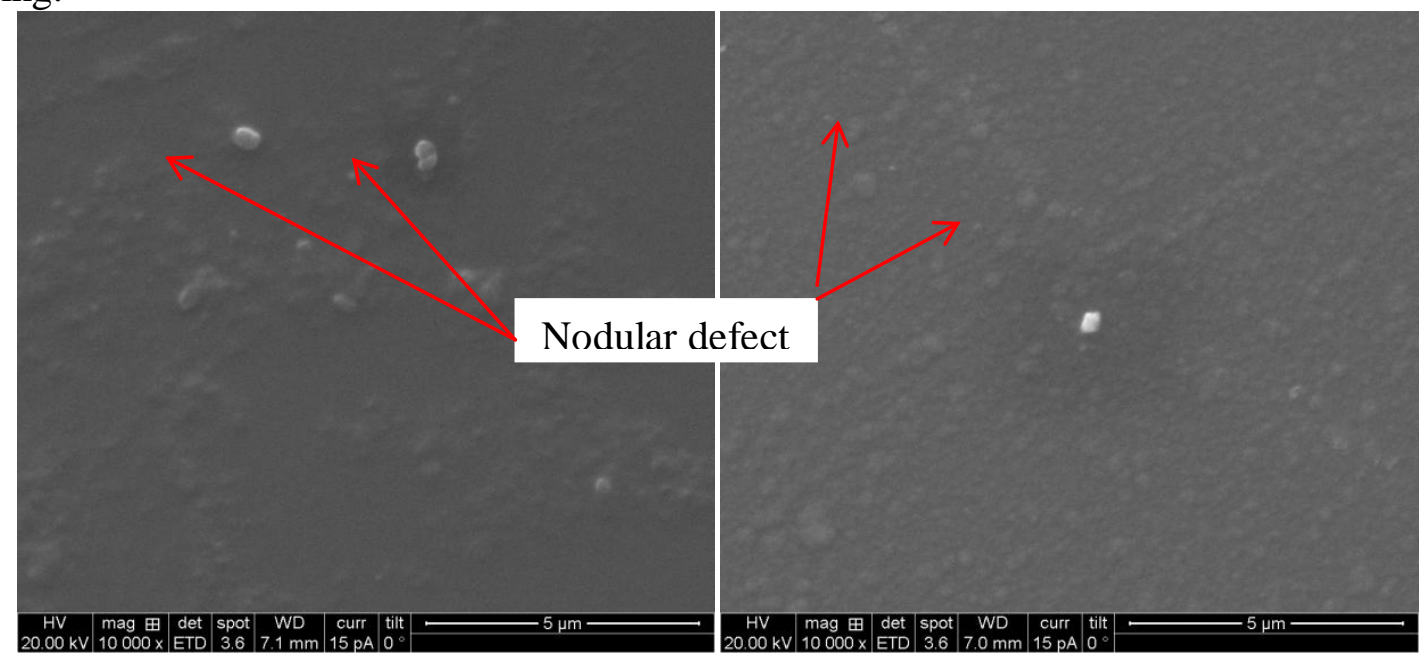

Fig. 6(b) SEM images showing nodular defects in NiCrAIY coating As-deposited NiCrAlY thin films
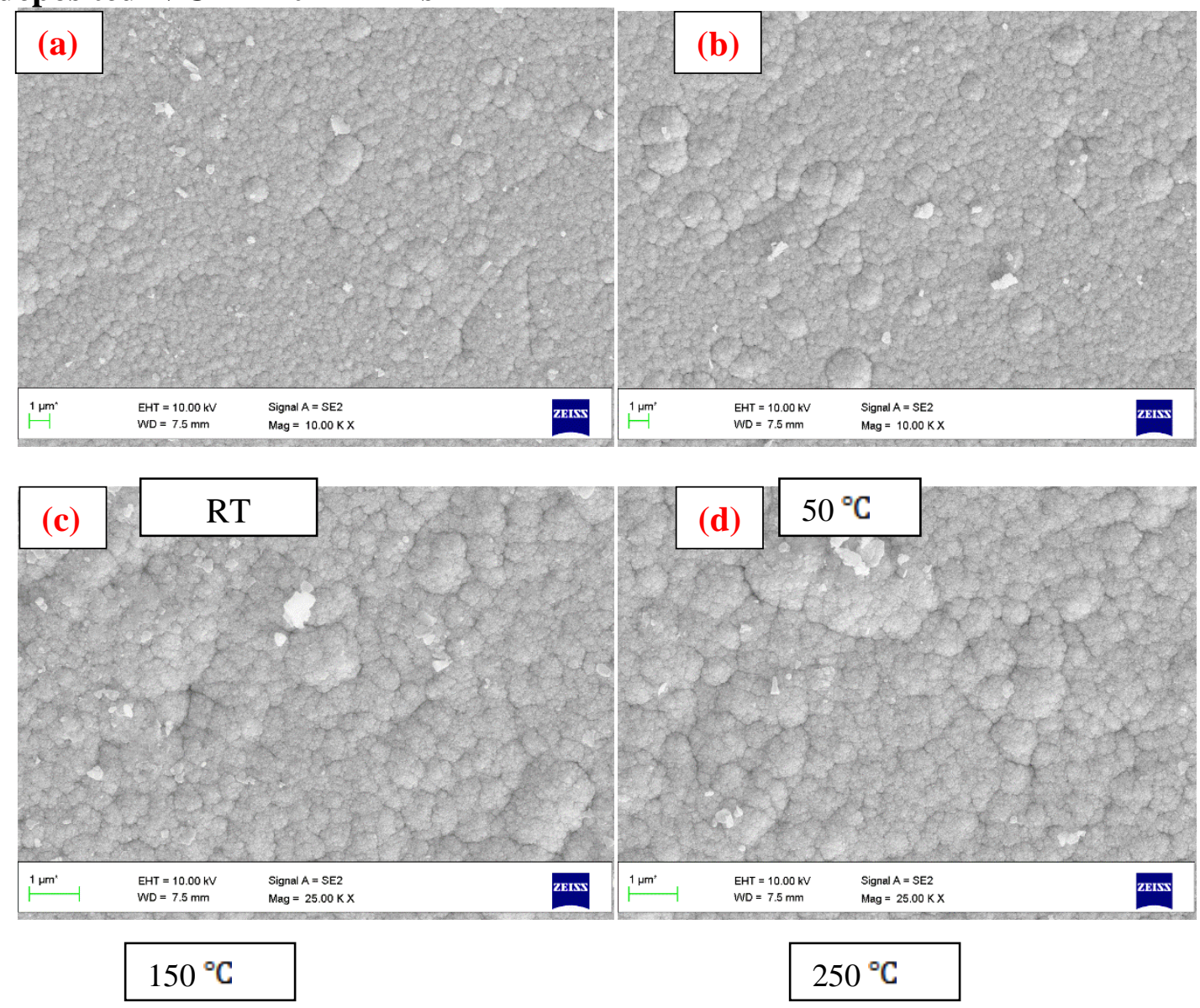

Fig. 7 FE-SEM images of as-deposited NiCrAlY coating

Fig.7 shows the FE-SEM images of the as-deposited NiCrAlY coatings under various deposition temperatures keeping the sputtering power constant at $150 \mathrm{~W}$. The coating 
deposited at room temperature (Fig.7(a)) showed dense continuous coatings on the surface. However, no major difference in microstructure was observed with the rise in substrate temperature. But the coatings exhibited relatively smoother surfaces which are globular in nature as the temperature is increased to $50{ }^{\circ} \mathrm{CFig} .7$ (b)). With increase in temperature, the coatings exhibited columnar nodular growth i.e. smaller atoms migrated across the coating surface to recombine with each other to form larger and denser agglomerated particles (Fig.7 (c, d) ). The SEM micrographs confirmed that the increase in substrate temperature resulted in marginalgrain growth and also evidenced that the film consisted of a number of polycrystallites.

\section{CONCLUSION}

The surface roughness of the coating in as-deposited and after thermal cycling was increased due to the formation of fine grain crystals and found to be $24.09 \mathrm{~nm}, 33.00 \mathrm{~nm}$ respectively. The microstructural evaluation showed dense continuous coatings on as-deposited NiCrAlY thin films. Whereas nodular nanocrystalline grains formation was observed due to thermal cycling effect.

\section{REFERENCES}

[1] Meiheng, Li., Xiaofeng, Sun., Wangyu, Hu., and Hengrong, Guan., "Microstructural changes and elemental diffusion of sputtered NiCrAlY coating on a Ni-base SC superalloy subjected to high temperature", Materials Letters., (61), 2007, pp. 5169-5172.

[2] Chen, Y., Zhao, X., Dang, Y., and P. Xiao, "Characterization and understanding of residual stresses in a NiCoCrAlY bond coat for thermal barrier coating application", Acta Materialia., (94), 2015, pp. 1-14.

[3] Curry, N., Markocsanc, N., Nylen, P., Mishra, S.K., Pandey, S., Mahato, M., Shravan Kumar, K., Bysakh, S., Sreemany, M., and Pathak, L.C., "Microstructural studies on EBPVD deposited NiCrAlY, YSZ and lanthanum zirconate for thermal barrier applications", Surface \& Coatings Technology., (207), 2012 pp. 143-148.

[4] Thin film sensor market website assessed on 20 Feb, 2015. Available:http://www.bccresearch.com/market-research/instrumentation-andsensors/ thinfilm-sensors-ias051a.html.

[5] Aniolek, G.E., Gregory, O.J., "Thin film thermocouples for advanced ceramic gas turbine engines", Surface and coatings Technology. 1994, pp. 68-75.

[6] Lei, j.F., and Will, H.A., "Thin film thermocouple and strain gauge technologies for engine applications", Sensors and actuator A., (65), 1998, pp. 187-193.

[7] Evans, G., Clarke, D., and Levi, C., "The influences of oxides on the performance of advanced gas turbines",Journal of the European Ceramic Society., vol. 28, 2008, pp. $1405-1419$.

[8] Hesnawi, A., Li, H., Zhou, Z., Gong, S., and Xu, H., "Effect of surface condition during pre-oxidation treatment on isothermal oxidation behaviour of MCrAlY bond coat prepared by EB-PVD”, Surface and Coatings Technology., vol. 201, 2007 pp. 6793-6796, 2007.

[9] Brandl, W., Marginean, G., Maghet, D., and Utu, D., "Effects on specimen treatment and surface preparation on the isothermal oxidation behaviour of the HVOF-sprayed MCrAlY coatings", Surface and Coatings Technology., vol. 188, 2004, pp. 20-26.

[10] Wu, Y., Qin, M., Feng, Z., Liang, Y., Sun, C., and Wang, F., "Improved oxidation resistance of NiCrAlY coatings”, Materials Letters., vol. 57, 2003, pp. 2404-2408. 